\title{
Outcome Measures and Psychomotor Skills Related to Shoulder Conditions for Clinical Orthopedic Training
}

\author{
Surreya Mahomed Saud Al-Obaidi Baker Al-Zoabi \\ Department of Physical Therapy, Faculty of Allied Health Sciences, Health Science Centre, Kuwait University, \\ Kuwait
}

\author{
Key Words \\ Physical therapy training • Outcome measures $\cdot$ Shoulder \\ pathologies
}

\begin{abstract}
Objective: This study was designed to assess the ability of physical therapy (PT) students to utilize selected outcome measures such as range of motion (ROM), pain and a number of psychomotor skills and to determine the efficacy of treatment they carried out during orthopedic clinical training. Materials and Methods: The clinical education booklets in orthopedics of all PT students over a 6-year period were reviewed. Students' application of psychomotor skills such as peripheral joint mobilizations (PJM), proprioceptive neuromuscular facilitation (PNF) techniques, therapeutic exercise techniques as well as utilization of basic outcome measures such as ROM and pain were analyzed with descriptive statistics and paired t test. Results: A majority of students used PJM techniques (78.6\%) and PNF techniques (58.6\%). The paired test indicated that treatment interventions used by the students were associated with improved shoulder joint ROM and decreased pain levels $(p<0.001)$. At the same time, therapeutic exercises were employed by the students after PJM and PNF. The most common 'comparable joint sign' was limitation in shoulder abduction ROM, which occurred in $44 \%$ of patients seen by the students. Conclusion: PT stu-
\end{abstract}

dents' application of PJM, PNF, and therapeutic exercise improved ROM and decreased pain in patients with shoulder pathologies.

Copyright $\odot 2008$ S. Karger AG, Basel

\section{Introduction}

Patients with shoulder pathologies are commonly seen in physical therapy. However, few large descriptive studies on this population have been published [1-4]. The studies that do exist often classify patients under the broad range of 'shoulder pain' or chronicity of shoulder pain $[5,6]$. A majority of shoulder complaints last for relatively long periods of time or recur. Approximately $50 \%$ of all patients who visit their general practitioner with a new episode endure complaints for up to 6 months and up to $40 \%$ still have complaints after 12 months [7-9]. Moreover, $46 \%$ of all patients recalled one or more prior episodes of shoulder problems [8]. In a study carried out in the general population in Sweden, $85 \%$ of patients with initial chronic shoulder pain still reported pain after 12 years [10].

The shoulder is the fourth most frequent site of musculoskeletal pain reported by patients to general medical practitioners and physical therapists, exceeded only by the neck, back and knee [6]. Shoulder pain is associated 
with significant disability and loss of quality of life. Significant difficulty with personal care has been reported by $20-30 \%$ of elderly study participants $[11,12]$. Many also reported difficulty with household duties $[11,12]$ and one quarter had disturbed sleep [11].

It has been reported that $27 \%$ of shoulder patients suffer from pain and $29 \%$ suffer some form of disability [13, 14]. Because shoulder complaints can have considerable impact on daily life and often develop into chronic disorders, it is important to train physical therapy (PT) students to optimize the treatment. When providing an intervention aimed at improving pain and range of motion (ROM), taking measures, before and after, would provide an assessment of outcome [15]. A 1998 survey of respondents indicated the use of important tools to establish outcome measures in PT practice as follows: ROM (90\%), manual muscle testing (88\%), goal setting $(73 \%)$, visual analogue scale and pain (57\%) [16]. Pain and ROM are used as proof of improvement in outcome measures because they are important features of shoulder joint pathologies [17]. The percentage of intervention techniques that were frequently used by physical therapists were as follows: exercise (99.6\%), passive mobilizations (57.0\%), and proprioceptive neuromuscular facilitation (PNF, 43.7\%) [18]. PT treatment consisted of passive joint mobilization and ROM exercises. Passive joint mobilization was used at the shoulder, sternoclavicular and acromioclavicular joints [6]. It is also generally accepted that healthy individuals and also persons with impairments are known to benefit from exercise [19]. It seems that there is a role for intensive mobilization techniques in the treatment of shoulder pathologies, especially in the case of adhesive capsulitis [17].

The present study was undertaken to assess the ability of PT students to utilize selected outcome measures (ROM and pain), and psychomotor skills [peripheral joint mobilizations (PJM), PNF and therapeutic exercises] in patients with shoulder conditions and also the effectiveness of the way they conducted the treatment.

\section{Subjects and Methods}

\section{Settings}

PT students, in the third year of their degree program at Kuwait University, were assigned to six different government hospitals in Kuwait for their orthopedic clinical training. The clinical affiliation consisted of three rotations, the duration of each being 1 month. Thus, each student had an opportunity to visit three clinical sites during their orthopedic training.

\section{Sampling}

Sixty-nine students, over a 6-year period, had their clinical orthopedic education booklets reviewed; during the rotation, students were given regular feedback about their performance, including its documentation.

\section{Instrumentation}

In this study, pain and mobility were the primary outcome measures consistent with the report that they were important features of shoulder pathologies [17]. The Numerical Pain Rating Scale (NPRS) measures the magnitude or intensity of pain. The individual is asked to select a number to represent the intensity of the pain at the moment. The total number of booklets was 147. Sixty PT students had an opportunity to assess and treat shoulder patients. A total of 134 shoulder pathologies were treated by students, of which 70 shoulder pathologies were randomly selected through a table of random numbers. The clinical education booklets contained student documentation of patient information regarding assessment and treatment. Students provided comprehensive patient information including biographical data, present history, past history, subjective and objective assessment, problem list, goal identification, and treatment plan. Clinical supervisors from the hospitals as well as clinical instructors from the university observed closely what the students were doing in the assessment and treatment of their patients. The scale is $0-10$, with 0 being no pain and 10 being the worst pain. It can be administered either verbally or in the written form [20]. All students in this study preferred to use the verbal form of feedback from the patient as they indicated the number representing the magnitude of pain. Goniometric measurement may be used to determine the total amount of motion available at a joint [21]. Students measured active ROM before and after treatment. They were trained in goniometric measurement and educated about intratester and intertester reliability.

\section{Procedure}

When examining the shoulder joint using the Maitland mobilization techniques, the primary aim is to establish a comparable joint sign (CJS). This refers to a combination of pain, stiffness and spasm that may be found on examination and considered being comparable with the patient's symptoms [22, 23]. For example, the patient may have pain and restriction of movement in flexion, abduction and lateral rotation of the shoulder joint. However, it is the lateral rotation which is the most painful and restricted that can become the CJS. The PT management is concentrated on the CJS with the intention of improving all other aspects of pain, ROM, and muscle spasm. For example, the student performed one third of the PJM treatment to guide him/her if pain and lateral rotation (CJS) had improved. After the complete treatment, pain and all ROM in flexion, abduction and lateral rotation were compared to establish if the PJM was working to improve all the ranges of motions and pain in the affected area.

\section{Data Analysis}

The data were analyzed using SPSS software. Descriptive statistics and paired t test were used to establish if pain decreased and the ROM increased in the shoulder joint pathologies treated. 
Table 1. Types of shoulder conditions referred to PT students

\begin{tabular}{lcc}
\hline \multirow{2}{*}{ Conditions } & \multicolumn{2}{l}{ Patients } \\
\cline { 2 - 3 } & $\mathrm{n}$ & $\%$ \\
\hline Frozen shoulder/adhesive capsulitis & 23 & 32.86 \\
Fracture shaft of humerus & 13 & 18.57 \\
Fracture surgical neck of humerus & 6 & 8.57 \\
Dislocation of the shoulder & 6 & 8.57 \\
Periarthritis & 5 & 7.14 \\
Nerve injuries & 5 & 7.14 \\
Supraspinatus tendinitis & 4 & 5.71 \\
Soft tissue injuries & 4 & 5.71 \\
Fracture of the clavicle & 1 & 1.43 \\
Separation of humeral epiphysis & 1 & 1.43 \\
Cut tendons & 1 & 1.43 \\
Deltoid tendinitis & 1 & 1.43 \\
\hline Total & 70 & 100.0
\end{tabular}

Table 2. Types of interventions used by PT students

\begin{tabular}{llc}
\hline Intervention & $\begin{array}{l}\text { Number of } \\
\text { times used }\end{array}$ & $\begin{array}{l}\text { Students } \\
\%\end{array}$ \\
\hline Therapeutic exercises & 70 & 100.0 \\
PJM & 55 & 78.6 \\
PNF & 41 & 58.6 \\
Hot pack & 41 & 58.6 \\
Cryotherapy & 22 & 31.4 \\
Ultrasound & 19 & 27.1 \\
Interferential therapy & 17 & 24.3 \\
TENS & 7 & 10.0 \\
Massage & 5 & 7.1 \\
Short wave diathermy & 2 & 2.9 \\
Hydrotherapy & 1 & 1.4 \\
Continuous passive motion & 1 & 1.4 \\
Medium frequency currents & 1 & 1.4 \\
\hline
\end{tabular}

TENS $=$ Transcutaneous electrical nerve stimulation.

\section{Results}

The mean age of the patient population was $43 \pm 1.8$ years (the range being from 11 to 77 years). The patients were treated 3 times a week during the students' 4 -week rotation. In total, each patient received 12 treatment sessions. Thirty percent of the patient population included in the present study was male and $70 \%$ female. The types of shoulder conditions that PT students treated were variable and included adhesive capsulitis, fractured shaft of

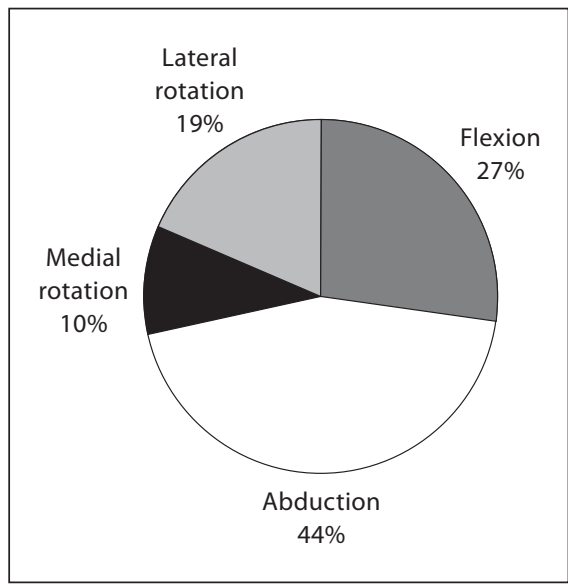

Fig. 1. CJS in patients with shoulder conditions as assessed by PT students.

the humerus, fractured surgical neck of the humerus, dislocation of the shoulder, periarthritis, and supraspinatus tendonitis (table 1). Adhesive capsulitis accounted for $32.86 \%$ of shoulder conditions referred for PT students' attention (table 1).

The majority of students used PJM techniques (78.6\%) and PNF techniques (58.6\%) to treat patients (table 2). All students used therapeutic exercise (100\%) after PJM and PNF. In this study, the most common CJS was shoulder abduction, being $44 \%$ of the patient population seen by PT students (fig. 1). The results of paired t test (table 3) indicated that patients with shoulder pathology who were treated by PT students did show significant improvement $(\mathrm{p}<0.001)$ in all ROM measurements and also showed reduction in their pain level measured by NPRS. Over a period of 4 weeks patients received 12 treatment sessions and experienced an increase in ROM with a mean improvement (measured in degrees) of $30.0^{\circ}$ of flexion, $21.0^{\circ}$ of abduction, $12.0^{\circ}$ of lateral rotation and $10.5^{\circ}$ of medial rotation. Patients also reported a decrease in pain with a mean reduction of 2.9 points for the NPRS. Similar significant improvements $(\mathrm{p}<0.001)$ were observed in patients treated with either PJM or PNF (table 3).

\section{Discussion}

The most common CJS according to Maitland's definition is shoulder abduction; this was present in $44 \%$ of the patient population seen by PT students, followed by flexion (27\%) and lateral rotation (19\%) (fig. 1). It is plausible that the measured improvements in ROM and pain 
Table 3. Effect of PT students' interventions on ROM and pain levels in patients with shoulder dysfunction

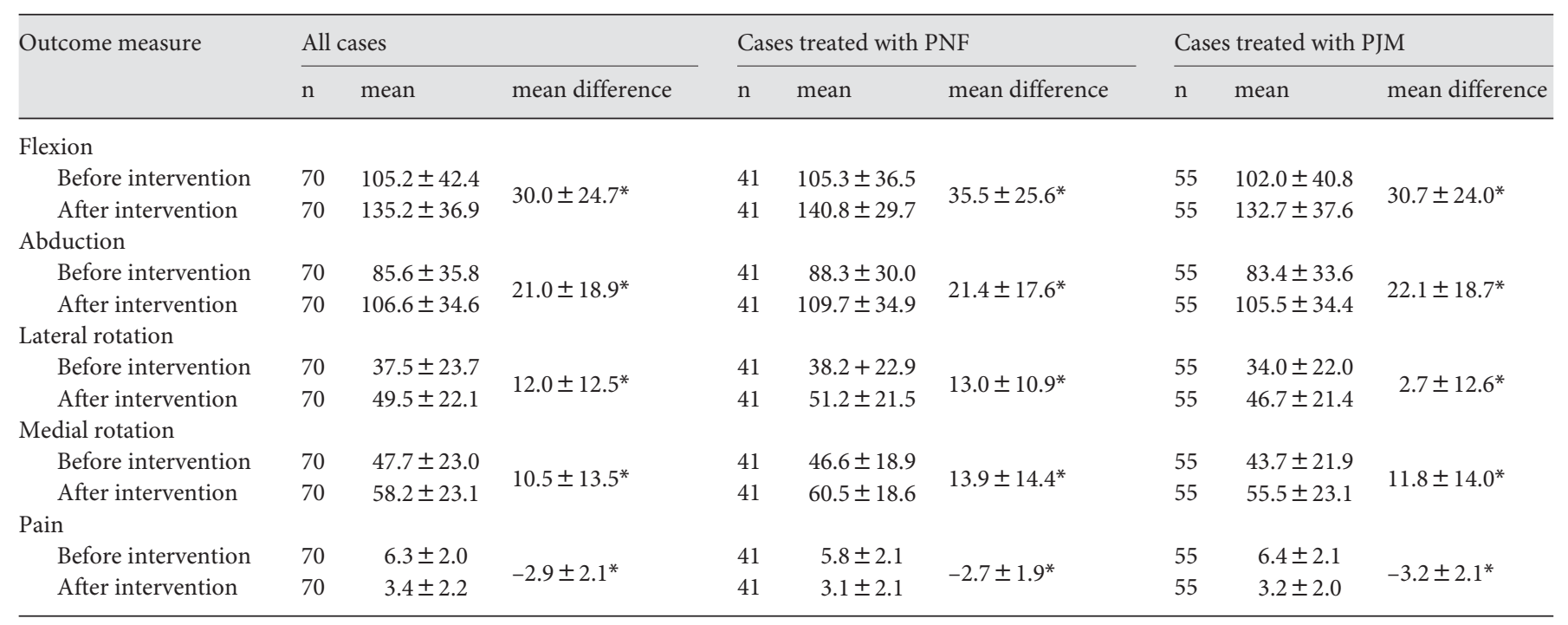

${ }^{*} \mathrm{p}<0.001$.

in the patients, while they were under the care of PT students, may have been partially due to spontaneous recovery in the shoulder complex $[24,25]$. However, PJM are believed to be an effective treatment for enhancing ROM and decreasing pain in patients with shoulder dysfunction [26]. Nicholson [27] reported significant improvement of passive shoulder abduction in patients with adhesive capsulitis who received joint mobilization combined with active exercise.

Exercise, passive mobilization and PNF are commonly used in the treatment of shoulder joint pathologies, especially in the case of adhesive capsulitis [17-19, 23, 27]. In an intervention aimed at improving patient satisfaction, assessment of outcome can be made by taking measures of pain and ROM before and after the procedure [15]. In the present study students achieved an increase in ROM and a decrease in pain at the shoulder of patients they treated. These results, however, do not allow ascertaining whether any particular intervention or a combination of them was responsible for the satisfactory treatment outcome. This needs further investigation.

One of the limitations of this study was that a no-treatment control group was not included. On ethical grounds it is not appropriate to include a no-treatment control group [6] or to withhold treatment for the 4-week period. Significant difficulty with personal care had been reported by $20-30 \%$ of elderly study participants [11, 12], with many also reporting difficulty with household duties [11,
12] and one quarter reporting disturbed sleep [11]. In the present study, use of a shoulder disability scale (SPADI, DASH, or American Shoulder and Elbow Surgeons Scale) would have helped to assess the change in impact of shoulder pain on everyday living over time.

According to van der Windt et al. [3], the concomitant diseases most frequently recorded with shoulder disorders were diabetes mellitus, ischemic heart disease [28], and systemic disorders of the musculoskeletal system (osteoporosis) [3]. As diabetes mellitus and ischemic heart diseases are very common in Kuwait [29], their association with shoulder pathologies and cervical spine warrant attention.

The greatest proportion of shoulder complaints is reported during the fifth to the seventh decades of life [30, $31]$, with a slight majority of patients being female (57$59 \%$ ) [28]. In the study reported here, $70 \%$ of the patients were female and $30 \%$ were male, but that reflected the relative number of therapists, not gender prevalence of shoulder complaints. Some community surveys have reported a high prevalence of chronic shoulder conditions in the elderly [32-34], suggesting that many elderly do not seek medical attention for a persisting painful or stiff shoulder. A community survey is needed in Kuwait to establish the prevalence of chronic shoulder conditions in the elderly. 


\section{Conclusion}

This retrospective study showed that PT students in their orthopedic assignment were able to obtain clinical and statistical decrease in pain and increase in ROM of patients with various shoulder pathologies. They were able to utilize appropriate outcome measures and apply psychomotor skills such as PJM techniques, PNF techniques and therapeutic exercises in the management of shoulder conditions.

\section{References}

1 Green S, Buchbinder R, Hetrick S: Physio- 11 Chakravarty K, Webley M: Shoulder joint therapy interventions for shoulder pain. Cochrane Database Syst Rev 2003;2: CD004258.

2 Hill JA: Epidemiologic perspective on shoulder injuries; in Jobe FW (ed): Clinic in Sports Medicine. Philadelphia, Saunders, 1983, pp 241-246.

3 van der Windt DA, Koes BW, de Jong BA, Bouter LM: Shoulder disorders in general practice: incidence, patient characteristics, and management. Ann Rheum Dis 1995;54: 959-964.

-4 Millar AL, Jasheway PA, Eaton W, Christensen F: A retrospective, descriptive study of shoulder outcomes in outpatient physical therapy. J Orthop Sports Phys Ther 2006;36: 403-414.

$\checkmark 5$ Geraets JJ, Goossens ME, de Groot IJ, de Bruijn CPC, de Bie RA, Dinant GJ, van der Heijden G, van den Heuvel WJA: Effectiveness of a graded exercise therapy program for patients with chronic shoulder complaints. Aust J Physiother 2005;51:87-94.

6 Ginn KA, Cohen ML: Exercise therapy for shoulder pain aimed at restoring neuromuscular control: a randomized comparative clinical trial. J Rehabil Med 2005;37:115122.

7 Kuipers T, van der Windt DA, Van der Heijden GJMG, Bouter LM: Systematic review of prognostic cohort studies on shoulder disorders. Pain 2004;109:420-431.

8 van der Windt DA, Koes BW, Boeke AJ, Deville W, de Jong BA, Bouter LM: Shoulder disorders in general practice: prognostic indicators of outcome. Br J Gen Pract 1996;46: 519-523.

-9 Winters JC, Sobel JS, Groenier KH, Arendzen JH, Meyboom-de Jong B: A Shoulder Pain Score: a comprehensive questionnaire for assessing pain in patients with shoulder complaints. Scand J Rehab Med 1996;28: 163-167.

10 Andersson HI: The course of non-malignant chronic pain: a 12 year follow-up of a cohort from the general population. Eur J Pain $2004 ; 8: 47-53$ movement and its relationship to disability in the elderly. J Rheumatol 1993;20:13591361.

12 Vecchio P, Kavanagh R, Hazelman B, King $\mathrm{R}$ : Community survey of shoulder disorders in the elderly to assess the natural history and effects of treatment. Ann Rheum Dis 1995;54:152-154

13 Van der Heijden GJ: Shoulder disorders: a state-of-the-art review. Baillieres Best Pract Res Clin Rheumatol 1999;13:287-309.

14 Picavet HS, Schouten JS: Musculoskeletal pain in the Netherlands: prevalences, consequences and risk groups, the DMC(3)-study. Pain 2003;102:167-178.

15 Kendall N: Developing outcome assessments: a step-by-step approach. NZ J Physiother 1997;25:11-17.

16 Kay TM, Myers AM, Huijibregts MPJ: How far have we come since 1992? A comparative survey of physiotherapists' use of outcome measures. Physiother Can 2001;53:268-275, 281.

17 Vermeulen HM, Obermann WR, Burger BJ, Kok GJ, Rozing PM, van den Ende CH: Endrange mobilization techniques in adhesive capsulitis of the shoulder joint: a multiplesubject case report. Phys Ther 2000;80: 1204-1213.

18 Turner PA, Whitfield TW: A multidimensional scaling analysis of the techniques that physiotherapists use. Physiother Res Int 1997;2:237-254.

19 Lamb S, Frost H: Exercise - the other root of our profession. Physiotherapy 1993;79:772.

20 Cole B, Finch E, Gowland C, Mayo N: Physical Rehabilitation Outcome Measures. Toronto, Canadian Physiotherapy Association, 1994.

21 Norkin CC, White DJ: Measurement of Joint Motion. A Guide to Goniometry, ed 2. Philadelphia, Davis, 1995.

22 Maitland GD: Peripheral Manipulation, ed 3. London, Butterworth-Heinemann, 1991

23 Maitland GD: Passive movement techniques for intra-articular and periarticular disorders. Aust J Physiother 1985;31:3-8.
24 Anton HA: Frozen shoulder. Can Fam Physician 1993;39:1773-1777.

25 Stam H: Frozen shoulder: a review of current concepts. Physiotherapy 1994;80:588-599.

26 Nitz AJ: Physical therapy management of the shoulder. Phys Ther 1986;66:1912-1919.

27 Nicholson GG: The effects of passive joint mobilization on pain and hypomobility associated with adhesive capsulitis. J Orthop Sports Phys Ther 1985;6:238-246.

28 Reeves B: The natural history of the frozen shoulder syndrome. Scan J Rheumatol 1975; 4:193-196.

29 Al-Shammri S, Shahid Z, Ghali A, Mehndiratta MM, Swaminathan TR, Chadha G, Sharma PN, Akanji AO: Risk factors, subtypes and outcome of ischaemic stroke in Kuwait: a hospital-based study. Med Princ Pract 2003;12:218-223.

30 Lamberts H, Brouwer HJ, Mohrs J: Reasons for Encounter-, Episode- and Process-Orientated Standard Output from Transition Project. Part I. Amsterdam, Department of General Practice/Family Medicine, University of Amsterdam, 1991.

31 Croft P: Soft tissue rheumatism; in Silman AJ, Hochberg MC (eds): Epidemiology of the Rheumatic Diseases. Oxford, Oxford Medical Publications, 1993, chap 15, pp 375-421.

32 Chakravarty KK, Webley M: Disorders of the shoulder: an often unrecognized cause of disability in elderly people. BMJ 1990;300: 848-849.

- 33 Chard MD, Hazleman R, Hazleman BL, King RH, Reiss BB: Shoulder disorders in the elderly (a community survey). Arthritis Rheum 1991;34:766-769.

34 Vecchio PC, Kavanagh RT, Hazleman BL, King RH: Community survey of shoulder disorders in the elderly to assess the natural history and effects of treatment. Ann Rheum Dis 1995;54:152-154. 